\title{
Algumas considerações sobre a infecção tuberculosa
}

\author{
Conferencia realizada no Instituto de Hygiene da Faculdade \\ de Medicina de São Paulo em 11 de Março de 1921 \\ PELO DR. A. FONTES
}

Permitti que, me aproveitando do convite que por parte do Instituto de Hygiene, gentilmente me fez meu prezado amigo, o Sr. Prof. GERALDO DE PAULA SOUZA, abuse de vossa condescendencia, repetindo aqui o que ha longos annos vem a experiencia me ensinando no estudo da infecção tuberculosa.

Nesse estudo devemos orientar as investigacões para o conhecimento exacto não só do elemento invasor como do organismo parasitado.

Não basta que o microbiologista conheça e determine as condiçóe de vida da causa etiologica, em seu desenvolvimențo cultural, pelo. reconhecimento ná lesões, mas necessario se torna que o biologista o acompanhe na evolução da infecção, investigando as alterações determinadas nos tecidos, as modificações physico-chimicas dos humores, as perturbações funccionaes dos systemas, e as reacções somaticas ou individuaes que constituem as armas de defeza organica, muitas vezes bem succedida com a eliminação do fóco infectuoso ou com oseu enkystamento.

A infeccão tuberculosa deve, meus senhores, ser considerada originariamente uma doença cellular. A penetração do bacillo de $\mathrm{KOCH}$ no organismo determina como phase primordial das reaccões de ¿defeza, a phagocytose do germen.

São os phagocytos, guarda avançada da defeza organica, que se incumbetm de oppor a primeira barreira á infecção. Dentre estes são as cellülas polynucleadas as que primeiro accodem, e então, englobando os elemientos infectuosos, limitam até certo ponto o seu poder invasor.

Em breve, porem, a cellula phagocytaria fica preza da infecção. Os: bacillos parasitam-n'a, transformando-a em meio propicio á sua proliferação, mercê da constituição chimica especial que os caracteriza e das armas offensivas de que dispõem, sufficientes para determinarem a morte da cellula parasitada, pela degeneração do seu substracto, e a consequente disseminação na corrente lymphatica ou sanguinea da primeira colonia desenvolvida "in vivo".

Vê-se, pois, meus senhores, que no estudo da infeccão tuberculosa se impõe o conhecimento aprofundedo e exacto da morphologia e da biologia do elemento infectuoso, para que melhor se possam compre hender as reaccões de defeza e para que com mais efficiencia se pos- 
sam investigar as causas da cura espontanea, os agentes therapouticos, physicos, chimicos ou biologicos, que a ella conduzam com mais segurança.

Tive, meus senhores, opportunidade de, em 1911, estudando a cytologia do bacillo de Koch, chegar a conclusões bastante interessantes e que se afastam do modo clasisico de conceber a morphologia do parasita em questão.

O bacillo da tuberculose se caracteriza dentre o commum das bacterias por propriedades especiaes, intimamente ligadas á sua constituição chimica e ainda derivante della, á sua constituição morphologica. Por inspecção microscopica, facilmente verificavein, se apresentam como pequenos bastonetes de constituição granulosa, que, por exame a fresco, sem coloração, em virtude da diversa refringencia de suas partes constituintes, deixam perceber sua estrutura differenciada. Si ao preparado fresco se addiciona uma gotta de solução de azul de methyleno, observa-se facilmente, que, em grande maioria, os corpos bacillares se conservam incolores, emquanto que em seu interior se apresentam granulações coradas em azul, variaveis em numero e em volume.

Nem todos os bacillos, entretanto, se conservam incolores; muitos tomam tambem o corante, e a razão de ser disso resulta da facil permeabilidade de uns e da impermeabilidade də outros, á custa de substancias especiaes, por elles formadas e que se sedimentam scobre o substrato material do germen, conferindo-lhe um revestimento a mordo de carapaça.

Essas substancias especiaes são constituidas por cêras, alcooes superiores, acidos graxos e gorduras neutras, phosphatides diversos, substancias todas conhecidas pela denominação generica de lipoides e que papel extremamente importante exercém não só na caracterização do germen como na evolução da infecção.

E assim que, em virtude dessa constituição chimica e morphologica especiaes deixam-se os bacillos de Koch caracterizar por methodos de coloração differenciaeis, de sorte a ser o seu reconhecimento facilitado entre o commum das bacterias, permittindo a elle, assim como ao numeroso grupo de outros germens que por esses caracteres lhes são affins, a constituição de uma grande classe, conhecida pelo nome de acido-resistentes.

Enquadram-se nessa classe todos os germens que apresentam a propriedade de, quando tingidos pelas cores de anilina, conservaremse corados após a acção descorante dos acidos diluidos. E essa propriedade lhes é, am geral, e, em particular ao bacillo de Koch, conferide pela constituição chimica, pelos diversos lipoides integrados nos corpos bacillares.

O estudo das granulações póde com vantagem ser proseguido por 
meio de preparados corados. Tomam intensamente o Garm, e são coraveis pelos methodos de Giemsa, Rosenbusoh, Delafield e Heidenhain.

Desses methodos, além daquelle, que apresentei em 1909 e que nada mais é que o metthordo de Ziehl, combinaldo ao de Gram, os de Delafield e Heidenhain são os que dão melhor resultado.

Praticando esses methodos, pude, em 1911 verificar que a granulação exierce na vida do bacillo da tulbericulose funcção essencial, comparavel áquella que é exercida pelo conidio nos cogumelos.

Alcompanhando o desenvolvimento de culturas homogeneas, verifican'do a proliferação de culturas commus em calldo ou mesmo em meios solidos, pesquizando em productos pathologicos, como escarros ou puz de natureza tuberculosi, verifiquei sempre que as granulações, por processo analogo á gemmulação, dão origem a outras granulações, que, por sua vez, se tornam centros de reprodução.

E' de prever que o phenomeno assim se passe, pois que vemol-as ligadas entre si por diligados fillamentos, constituindo grumos, não apresentando em inicío de cultura ainda o caracter de acido-resistencia, e conservando um notavel parallelismo nos corpos bacillares, facilmente reconhecivel, após a sedimentação dos constituintes lipoides, quis por seu peso determinam uma clivagem, permittindo a selparação dos bacillos nos grumos, consequente á ruptura dos filamentos unitivos. Por esse processo se faz, pois, a divisão da "colonia de granulações": em um ou outro sientido, de accordo com o plano de ruptura, permittinido a constituicãa de "bastonetes": em cujo interior as granulações guardam sensivel correspondincia.

Observam-se mesmo granulações isoladas, dando origem a outras que, mais tarde constituindo novos grumos, formarão novos bastonetes.

Assim pois como agente da infecção tuberculosa deve ser considerado o "virus granular", sendo a forma de bastonete, forma secundaria da sua evolução, termo superior no seu desenvolvimento.

A demonstração reciproca nos é dada, quando estuldamos a reacção de defeza, opposta pelo organismo invadido, com a constituição da forma granular, reconhecivel facilmente no puz de natureza tuberculosa.

O phagogyto inicialmente parasitado morre por não poder oppor barreira á acção toxica dos productos elaborados peló virus; a a caraupaça, que a este envolve, protege-o efficazmente da acção vulnerante dos principios cellulares, que a elle se possam oppor.

E' a reacção secundaria, determinada pela barreira lym'phocytaria, que, intervindo com a producção de fermentos especiaes lipolyticos, consegue a destruição dessa carapaça, e, ainda que insufficientemente, torna o inimigo algum tanto vulneravel. 
O estudo do puz de natureza tuberculosa mostra a existencia nelle de um fermento de origem lymphocytaria, reconhecido por mim, por BERGEL e por FIESSINGER, e por PIERRE MiARIE, capaz de transformar não só "in vivo" como "in vitro" a forma bacillar acidoresistente em forma granular que $\mathrm{MUCH}$ descreveu contemporaneamente com minhas observações. Pelo estudo, a que em tempo procedi, desse fermento fui levado á convicção da sua acção estrictamente lipoilytica, sendo completamente inactivo sobre a forma granular, que persiste e que permanece como causa infectante. A carencia de fermentos proteolyticos, ligada á ausencia dos polynucleares, que, no curso da reacção de defeza, foram substituidos pelos lymphocytos, razão porque esses fermentos não existem no puz de natureza tuberculosa, expplica a permanencia do virus, que só pela inversão da formula leucocytaria seria attingivel, como experimentalmente se observa pela applicação de diversos agentes-modificadores, taes o iodo, a aleurona, os levedos, substancias estas eminenteménte excitadoras da funçã̃o microphagica.

Vemos pois que as reacções de defeza iniciaes cellulares fallecem em virtude da constituição chimica e estructural do virus, não só pelos venenos necrośantes, que o acompanham, como as constatações. de AUCLAIR e PARIS deixaram bem patente, assim ainda pelas substancias não reabsorviveis, constituintes do seu pseudo-envolucro.

Além disso, produz o virus em estudo venenos diffusiveis que se manifestam pela acção a distancia, influenciando os diversos systemas. da economia, e desses principalmente o systema nervoso, base do dynamismo da vida.

A mistura por demais complexa desses venenos constitue, meus senhores, quando produzida no caldo artificial de cultura, aquillo a que se dá o nome de tuberculina.

E' pois a tuberculina o resultado do metabolismo de uma cultura de tuberculose em caldo glycerinado, e age esse producto não só pelos principios elaborados pelos germens, diffusiveis e adherentes aos. corpos microbianos, como ainda por aquelles que resultam da complexa alteração do meio nutritivo, pela degradação dos principios albuminoides aos termos finaes de acidos aminados.

Manifestam esses venenos,entretanto, diversamente sua acção sobre o organismo hygido ou infectado por tuberculose. No primeiro caso a acção toxica é diminuta: as forças defensivas organicas se oppõem de tal sorte ao seu effeito malefico que em breve prazo a economia delles se liberta, sem mesmo nada accusar que indique alteração da saúde. No segundo caso, porém, os factos se passam diversamente. 
Reacções intensas se manifestam e algumas vezes de tal modo violentas que causam a morte do animal infectado.

Reconhece-se, pois, no organismo tuberculisado hypersensibilidade aos toxicos, elaborados pelo agente infectuoso, e, sendo esse phenomeno estudado cuidadosamente, até certo ponto póde se proceder á dissociação dăs reacções decorrentes dessa hypersensibilidade, o que permitte um conhecimento mais exacto da physio-pathologia da tuberculose.

Um bom methodo de analysie da funcção toxica e hypersensibilizante das tuberculinas é o que póde ser praticado pela inoculação de uma solução diluida desse toxico na pelle ou mucosa dos individuos tuberculosos.

Reconhecer-se-á ẹtão, que os elementos cellulares são influenciados por esse agente, pois que no ponto da inoculação constatar-se-á primordialmente um affluxo de polynucleares, seguido de lymphocytose. A reacção cellular é acompanhada de vaso-dilatação dos capillares, o que dá ao ponto de inoculação o aspecto da reacção inflammatoria local.

Forma-se com a exudação lymplhatica uma vesicula ou uma pequena papula, circumdada pela reacção inflammatoria.

Não são somente as cellulas que receberam o contacto directo dos venenos tuberculinicos as que se mostram sensiveis a elles. As cellulas do sangue, cuja crase morphologica é profundamente alterada, e principalmente as cellulas nervosas reagem nitidamente á solicitação tuberculinicar.

Essas ultimas manifestam mesmo uma acção fixadora notavel sobre esses venenos. A substancia nervosa cerebral, posta em contacto com a tuberculina, fixa-a de tal sorte que mesmo apóz lavagens successivas para a retirada dos principios toxicos, quando inoculada em animaes tuberculisados, permitte que a reacção da hypersensibilidade se manifeste. Algumas vezes esta reacção é mais intensa do que quando praticada com o uso da tuberculina isoladamente, phenomeno que está intimamente ligado á constituição chimica do elemento nervoso, muito rico em substancias lipoides que resise caso agem como fermentos activadores dos processos enzymaticos.

Da accão exercida pelas tuberculinas solbre as cellulas deriva nati:ralmente sua influencia sobre os systemas e, concomitantemente, sobre as reações de defeza somaticas.

Os systemas vasculares lymphatico e sanguineo, e o systema nervoso são os que mais facilmente deixam perceber essa influencia. As modificações da formula leucocytaria, a leucopenia, a migração leucocytaria para os fócos da infeç̧ão, os phenomenos congestivos; manifestados nos territorios vascularisados em gráu proporcional a 
essa vascularisação, os phenomenos hyperou hypotensivos, a hyperou hypothermia, e até as psychoses, mostram todos esses factos morbidos profunda alteração no synchronismo funccional, estrictamente dependentes da intoxicação do elemento nervoso.

Desses fectos, d’rivam, entretanto, meus senhores, as reacções de defeza. Quer cellulares quir humoraes, são hoje em dia essas reacções reconhecidas por todos os que se dedicam a esses esitudos.

Tive já opportunidade de referir que, em meu modo de ver, o

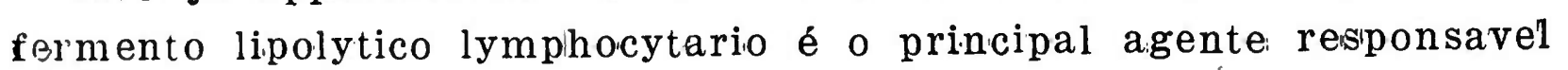
pela transformação da forma bacillar em forma granular.

Ainda que não se possam referir de modo absolutamente certo determinadas reacções a determinados venenos bacillares, a experimentação e a clinica mostram relações notaveis entre os dois termos da equação pathologica.

Parece fóra de duvida ser a reacção lymplholcytaria, com a libertação do fermento lipolytico, arma de defeza poderosa contra as gorduras neutras e cêras do bacillo de Koch.

A experimentação, a que em tempo procedi em colbayas, demonstrou a possibilidade de se modificar a evolução da infecção experimental nesses animaes ,quando são tratados com extractos glycerinados dos ganglios tuberculisados caseosos de boi, ricos em fermento lipolytico.

Observa-se nos animaes em experiencia. a activação dos processos de defeza, com a eliminação dos ganglios tuberculisados, que rapida. mente se transformavam em púz, com a libertação desse púz, pela ruptura dos abscessos formados, e, o que é ainda notavel, com a rapida cicatrização das ulceraçõ es resultantes, sem que se constituissem fistulas, como é a regra nessa infecção.

O typo clinico da infecção se modificava tambem, apresentando os animaes em experiencia, tuberculides generalisadas, indice de uma attenuação do virus.

Infelizmente, essa attenuação não se mostrou sufficiente para evitar a morte dos animaes, que succumbiram em prazos mais longos que as testemunhas, mas, que, pela necropsia, revelam a generalização da infecção. Facto interessante observei tambem, encontrando difficilmente bacillos acido-alcool-resistentes nas lesões examinadas, onde abundava o virus sob a forma granular.

Outros venenos, entretanto, que acompanham o bacillo, actuam directamente sobre os fermentos oxydantes, que são a base da respiração cellular.

A verificação que eu e PINTO fizemos na infecção experimental do coelho nos mostrou a constante diminuição do valor catalasico do sangue. 
A baixa mais accentuada se manifestava após a injecção do virus, - nos dois dias que se lhe seguiam, e depois se mantinha esse valor, decrescendo dia a dia até a morte do animal, ou se se elevava um pouco, não attingia nunca mais as proximidades do valor inicial. Era notavel e constante a discordancia, existente sempre no inicio da relação do animal á infecção, entre a curva thermica e a curva do valor catalasico. (Vide a curva abaixo)

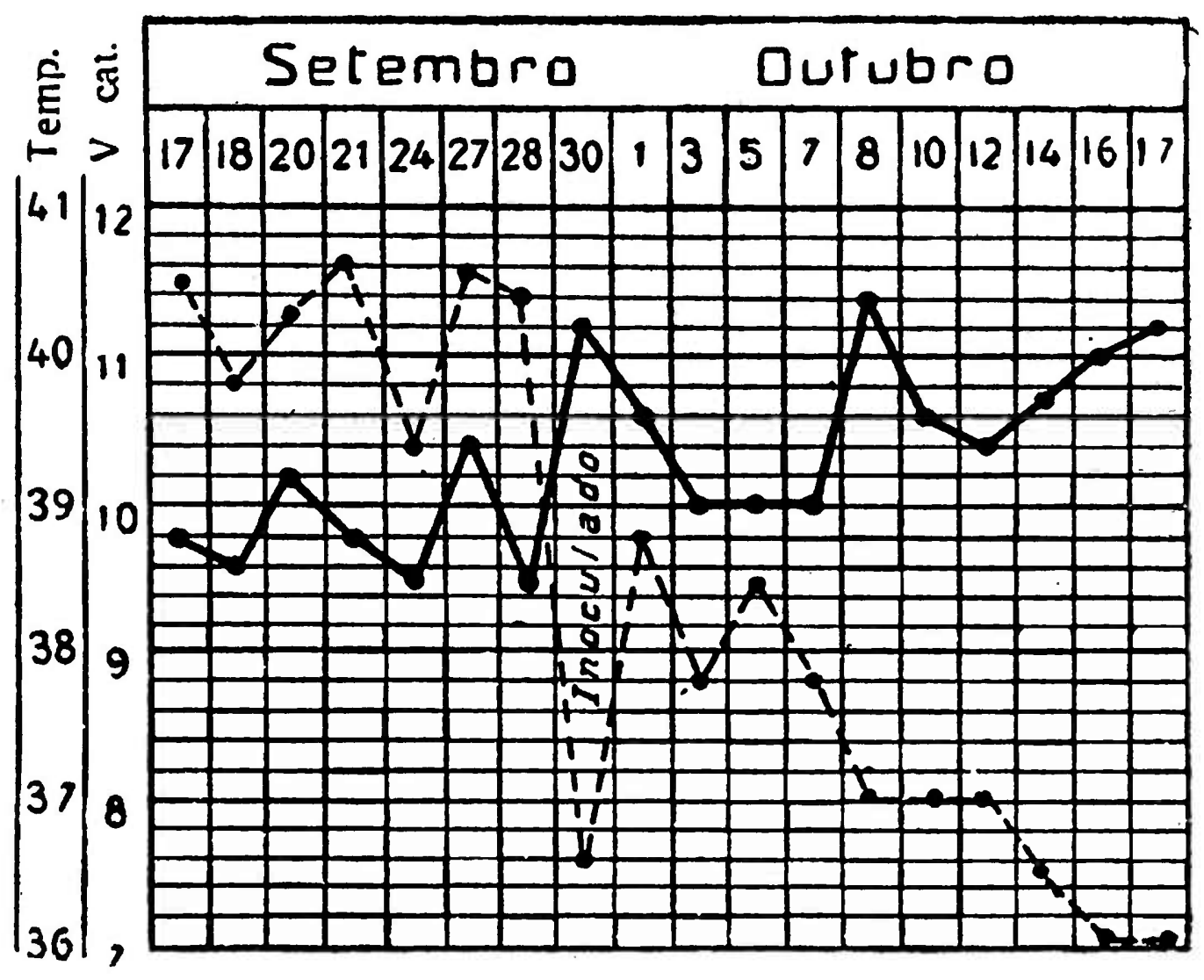

No homem, um dos meus discipulos, LOURENÇO DE ANDRADE, verificou que na infecção pulmonar, quando o valor cataliasico do sangue se acha augmentado, coincide esse augmento com uma formula hemoleucocytaria de prognostico favoravel.

Mantendo-se esse valor sem alteração sensivel no inccio da infeç̧ão tuberculosa e sem que haja nenhuma relação entre o valor catalasico e a curva thermica, baixa elle nos periodos finaes da infecção. 0 exame hematologico dos doentes em estudo mostrou que:

a) o augmento do valor catalasico do sangue acompanha o numero de hematias;

b) não ha relação constante entre o augmento das hematias e o augmento do valor catalasico do sangue no mesmo individuo;

c) não existe relação entre o valor catalasico e o numero de leucocytos;

d) as variações dos leucocytos, expressas nas formulas hemoleu- 
cocytarias, não acompanham regularmente as variações do poder catalasico do sangue.

A despeito das profundas alterações do metabolismo organico, determinadas pela intoxicação tuberculinica, o organismo tuberculisado reage, mobilisando suas forças defensivas, permittindo que a tuberculina, nelle inoculada repetidamente em dóses progressivamente crescentes, possa produzir um estado de immunidade "relativa" que se traduz pela existencia no sôro desses animaes de substanclas que se oppõem á sua acção hypersensibilizante.

Poderiam, pois, as reacções da defeza á intoxicação tuberculinica ser aproveitadas com objectivo therapeutico, sem inconveniencia maior, se os phenomenos de hypersensibilidade não se manifestassem ás mais das vezes de tal sorte violentas que pudessem chegar a pôr em risco a vida dos organismos infectados. Esses phenomenos, que ha uma dezena de annos vêm sendo estudados por grande numero de biologistas, ainda hoje se mostram obscuros em sua essencia, não tendo a sciencia encontrado para elles explicação cabal.

A que é devida a reacção especifica tuberculinica ?

WHITE e AVERY attribuem-n'a a uma toxi-proteina bacillar, com que determinam phenomenos de anaphylaxia em cobayas. WHITE nega mešmo qualquer funcção hypersensibilizante aos lipoides. THIELE e EMBLETON obteem, entretanto, a formação de anticorpos pela inoculação de phosphatides extrahidos dos bacillos da tuberculose, isentos de albuminoides, á prova de reaccão da ninhydrina. Pensam ainda esses mesmos autores que os phosphatides bacillares podem tornar cobayas hypersensiveis não só a elles proprios como ainda ás proteinas do bacillo, determinando phenomenos de anaphylaxia identicos aos obtidos com a proteina bacillar. A previa sensibilisação desses organismos pela proteina bacillar permitte que a inoculação posterior do phosphatide os possa ainda reproduzir. LESCHKE e MUCH interpretam os phenomenos de hypersensibilidade de modo diverso, acreditando que as reaccões, determinadas pela tuberculina, não sejam uniformes e que dependam das diversas substancias que a compõem. Não só as substancias albuminoides, como as de natureza graxa, as toxinas, dissolvidas como as volateis, podem provocar uma reacção de hypersensibilidade.

De modo analogo pensa DEYCKE, que reconhece acções especificas diversas aos productos que obteve pela dissolução dos bacillos em acido lactico e que funccionam como antigenos parciaes.

Em meu modo de ver,. e de acordo com o que a experiencia me tem ensinado, na infecção tuberculosa se manifesta um estado especial de hypersensibilidade aos venenos do virus que "não é identico" a os estados conhecidos em biologia pela designação de anaphylacticos. 
Acredito que esse estado de hypersensibilidade seja a expressão de uma modalidade reaccionaria, especial á cellula sensibilizada, que reage individualmente e de modo autonomo.

Tive, em 1917, occasião de publicar uma observação, que me autorisou a pensar desse modo.

Tratava-se de um doente com uma lesão tuberculosa ocular, cujo diagnostico clinico fôra confirmado por uma cuti-reacção positiva. Após ter cessado o periodo reaccionario, foi instituido o tratamento tuberculinico, em cujo decurso se manifestou intensa reacção, traduzida por uma psoriasis do antebraço, onde "dous mezes antes" havia sido praticada a reaccão diagnostica e pela revivescencia da reacção especifica. Da intensidade da reacção havida a seguinte gravura dá poderoso testemunho.

Assim, o organismo tuberculoso, não obstante ser localizada a inf̣eção, reagiu primeiramente pela "cuti-reacção"; a tuberculinização do paciente deterininou uma hypersensibillidade das cellulas que anteriormente haviam reagido, e cuja reacção cessara dous mezes antes, permittindo uma reactivação da reação de v. PIRQUET, que se mostrou então mais intensa que da primeira vez, e o apparecimento de uma lesão nova (psoriasis).

A differença reaccionaria nesse antebraço por elementos cellulares da miesma natureza, solicitados pelo mesmo principio toxico, não encontra explicação flacil e mostra que cellulas do mesmo tecido, no mesmo individuo, solicitadas peló mesmo toxico, podem agir de modo autonomo, individualmente e diversamente.

Não obstante, meus senhores, as reacções de hypersensibilidade, que sobremodo agravam a infecção tuberculosa, reconhecem todos os experimentadores a existencia de um estado de immunidade natural ou adquirida, facilmente demonstravel pela experimentação e pela clinica, e que nos organismos já tuberculisados póde ser obtido pela pratica de immunisação antituberculinica.

A experimentação nos ensina que o organismo hygido ou tuberculisado reage diversamente a uma inoculação do virus, quando feita sob a pelle. Nos animaes refractarios, se se faz uma inoculação do virus tuberculoso sob a pelle, verifica-se que os bacillos englobados pelos macrophagos no ponto da inoculação, geralmente não se multiplicam e, ahi aprisionados, acabam por perder a sua virulencia, sem determinarem alteração na saúde do animal experimentado. E' a demonstração da immunidade natural ao virus tuberculoso.

Nos animaes sensiveis os factos se passam de modo diverso. Se em uma coibaya sã se inocula sob a pelle uma emulsão de bacillos de tuberculose, se estabelece logo uma pequena reacção inflammatoria local, 
que entre a primeira e a segunda semana se indura. Após esse periodo, o ponto de inoculação se abceda, a pelle se rompe, dando escoamento ao puz formado, e a ulcera, assim produzida, de accordo com a virulencia do germen, tarda a cicatrizar ou permanece aberta, como é a regra, até a morte do animal, por generalisação da infecção. A esta ulcera dá-se o nome de cancro tuberculoso.

De modo diverso se passam os factos, quando a infecção é produzida em um animal já tuberculisado. Nestes não mais se forma o abcesso no ponto da inoculação. A pelle ao redor delle apresenta uma coloração violacea, mais ou menos carregada, torna-se negra, e ao cabo de uma dezena de dias a ulceração estabelecida pela necrose da pelle cicatriza de modo definitivo, sem que tenha havido repercussão inflammatoria dos ganglios das regiões circumvizinhas. E' este o phenomeno de Koch, base de toda a experimentação na immunisação anti-tuberculosa. As verificações de grande numero de experimentadores estabeleceram que as tuberculoses de reinfecção tomam sempre uma marcha chronica, e entre aquelles BENZAÇON e SERBONNES mostraram que na cobaya as reinfecções precoces, praticadas entre o 1." e o 15.0 dia após a primeira infecção, determinam abcessos. Somente após a primeira quinzena é que o phenomeno de Koch se manifesta com certa nitidez.

A observação clinica acha-se de accordo com os factos experimentaes. A lei de MARFAN, enunciada em 1886 e que diz que não se constata quasi nunca tuberculose pulmonar, ou pelo menos, tuberculose pulmonar evidente e em evolução, em individuos que na infancia soffreram de escrofulas (adenite tuberculosa suppurada do pescoço) e que curaram completamente antes dos 15 annos de idade, tendo sido obtida esta cura antes que qualquer outro fóco de tuberculose tenha se manifestado, encontra a sancção da observação clinica e da expe.. riencia, desde que se lhe restrinja até certo ponto a interpretaçĩo, reconhecendo como verdade que o organismo já tuberculisado reaje ás superinfecções, eliminando mais rapidamente os fócos onde ellas se acham localisadas em virtude da crescente hypersensibilidade.

Por outro, lado, meus senhores, a verificação da existencia de anticorpos em liberdade nos organismos tuberculisados, produzidos em virtude da immunização tuberculinica, tem sido observada pela grande maioria dos Autores.

"A tuberculina póde determinar por inoculações repetidas em animaes sensiveis, sãos ou tuberculosos, um estado de immunidade relativa, que se traduz pela existencia no sôro desses animaes, de substancias que se oppõem á sua funcção hypersensibilizante"

A maior difficuldade na pratica da therapeutica immunizante 
resulta cả intensidade das reacções, obtidas, que, não raras vezes, prejudicam o doente, levando a descredito o tratamento especifico.

As verificações iniciaes de WASSERMANN e TAKAKI, com a toxina tetanica e emulsão de cerebro e medulla, abriram novos horizontes nessa via de investigação, mostrando a possibilidade de neutralização das toxinas pelos lipoides, permittindo a formação de um complexo atoxico.

Os estudos posteriores de BEYER, CALMETTE, LEMOINE $\theta$ GERAD ISCOVESCO, PRIBRAM e RAUBISTCHECK permittem concluir que os lipoides bilíares neutralizam a tuberculina a ponto de impedir os phenomenos de oculo-ou de cuti-reacção nos organismos tuberculisados.

Retomando esses estudos, tive, meús senhores, opportunidade de chegar ás mesmas conclusões que os autores acima citados e verificar ainda por experimentação em individuos tuberculosos que: "a tuberculina tratada em determinadas condições pela lecithina e pela cholesterina, pelos lipoides da bile e pelos lipoides e outros principios mal definidos do oleo de figado de bacalhau se mostra com suas propriedades hypersensibilizantes attenuadas e póde ser empregada em serie therapeutica, sem receio de phenomenos reaccionaes prejudiciaes, conservando, entretanto, propriedades immunisantes e curativas".

Como poderemos explicar a acção attenuadora dos lipoides sobre as toxinas, e, no caso particular de que nos occupamos, sobre a tuberculina?

Como deixei atraz enunciado, para mim é facto fóra de duvida que a reacção hypersensibilizante é uma reacção originariamente cellular, autonoma e individual. Torna-se pois necessario que o toxico penetre na intimidade da cellula para que a reacção se produza e é ahi em seu interior que as reacções de defeza primordiaes devem se passar para que haja destruição do veneno e consequentemente fique a cellula illesa.

Ora, sabemos hoje em dia, o papel preponderante que cabe aos lipoides na regularização dos actos vitaes. Todos os biologistas reconhecem as correlações intimas entre esses corpos e os fermentos cellulares, activando-os ou impedindo-os em acção synergica. Assim, pois, os lipoides biliares e do oleo de figado de bacalhau manifestam, quando.ligados aos principios hypersensibilizantes da tuberculina, a propriedade de permittir-lhes uma absorpçâo lenta e gradual pelo elemento cellular sensivel, e agindo como activadores dos processos enzymaticos intracellulares, favorecem uma elaboração digestiva mais perfeita, e, consequentemente, uma melhor producção de anticorpos.

Dahi, meus senhores, o poder se considerar a tuberculina excellente arma para a therapeutica e para a prophylaxia da infecção 
tuberculosa; e, se acaso o seu uso não se tem generalizado nesses objectivos é que o preconceito, creado pelos insuccessos das applicações dos primeiros annos, permanece ainda arraigado no pensar dos clinicos, que a não experiementam, a isso levados exclusivamente pela repetição dos livros ou pelos resultados falhos de observações mal conduzidas.

Posso vos asseverar, meus senhores, que as propriedades, impedienteś ás reacções hypersensibilizantes, reconhecidas aos lipoides da bile e do oleo de figado de bacalháo, assim como a outros principios mal definidos existentes nesse oleo, permittem obter uma tuberculina que póde ser empregada em serie therapeutica, sem determinar reacções prejudiciaes, desde que se observem as regras comesinhas de immunização, tuberculina que conserva em alto gráu seu valor immunizante e therapeutico.

A minha observação clinica e a de varios collegas autorizam-me a assim pensar.

A tuberculina deste modo preparada tem sido largamente emprebada nas mais variadas formas clinicas da infecção com os resultados que passo a referir:

a) tuberculose pulmonar incipiente febril: cura verificada após 2 annos (Obs. do Snr. Dr. E. TORNAGHI);

b) tuberculose pulmonar apyretica com eliminação de bacillos: cura que se mantinha 6 mezes depois (Obs. do sr. Dr. SALGADO LIMA);

c) tuberculose pulmonar febril com eliminação de bacillos: cura observada dous annos e meio após a terminação do tratamento (Obs. do Sr. Dr. BASTOS D'AVILA);

() tuberculose pulmonar, congestiva, febril, com eliminação dé bacillos e evolução sub-aguda: cura verificada 2 annos depois de terminado o tratamento (Obs. do Sr. Dr. CARDOSO FONTE);

e) tuberculose pulmonar; fórma congestiva, hypertensiva, sem eliminação de bacillos: cura verificada 1 anno após (Obs. do sr. Dr. SALGADO LIMA);

f) tuberculose chronica febril, lesões bi-lateraes extensas: obito por grippe intercurrente, 1 anno após o inicio do tratamento, tendo sido conseguida a apyrexia, o augmento de peso e melhoria do estado geral (Obs. do sr. Dr. BASTOS D'AVILA);

g) tuberculose ganglionar fistulizada: cura constatada 6 mezes depois (Obs. do sr. Dr. CAMILLO DA FONSECA);

h) lesão tuberculosa ocular e concomittante infecção pulmonar: cura comprovada 6 mezes depois (Obs. do sr. Dr. MARIO GOES);

i) pharyngo-laryngite tuberculosa e tuberculose pulmonar: cura 
comprovada 6 mezes depois (Obs. dos srs. drs. LEAL NETTO e SALGADO LIMA);

j) psoriasis e tuberculose pulmonar: cura da psoriasis e grande melhoria do estado pulmonar (Obs. do sr. Dr. SILVA ARAUJO);

k) tuberculose renal e cystite tuberculosa: grande melhoria comprovada 1 anno depois de terminada a 1." etapa do tratamento (Obs. do Autor e do sr. Dr. JORGE DE GOUVÊA);

1) lupus erythematoso: cura do paciente (Obs. do sr. Dr. SILVA ARAUJO);

m) infecção tuberculosa latente - Purpura: cura antes de terminada a serie therapeutica (Obs. do sr. Dr. SILVA ARAUJO);

n) conjuntivite phlyctenular da 1." infancia: cura que se verificou antes de terminada a serie theraneutica (Clinica dos srs. Drs. FERNANDES FIGUEIRA e ARISTEU DE ANDRADE).

Permitti, meus senhores, que em pormenor eu vos demonstre a innocuidade desse agente therapeutico que resalta da seguinte observação:

Tuberculose pulmonar congestiva, febril, com eliminação de bacilló e evolução sub-aguda.

\section{Clinica do DR. CARDOZO FONTE}

Obs. n.' 4. - Senhorita'M. X. B., de 17 annos de idade. Peso 38 kilos e 100 grammas, doente desde abril de 1918. Inicio do tratamento em àgasto de 1918.

1.: quinzena de agosto: Temperaturas que oscillavam entre 36. $42 ., 2$ muita tosse, escarros sanguineos e suores noturnos.

2.a quínzena de agosto: A doente sujeita ao repouzo absoluto em leito e ao tratamento clinico adequado, manteve-se com temperaturas que oscillarvam entre 35,5 e $39^{\circ}, 5$, até 24 de agosto dia em que lhe loi feita a injecção da primeira dose de T. O. B2. A esta dose a doente reagiu, 5 dias depois, com a temperatura de $39 \mathrm{c}, 5$, isto é, 1 grau e 5 decimos acima da maxima constatada no dia da injecção. Os escarros sanguineos, a tosse e os suores continuaram.

1. quinzena de setembro: No dia 3 , foi-lhe feita applicação repetida cla 1. dose; não houve reacção thermica. antes a temperatura cai. lintamente com oscillações de $35^{\circ}, 3$ a $38^{\circ}, 37^{\circ}, 5,37^{\circ}, 7,37^{\circ}, 5$. Contiiluava a tosse muito forte com abundante expectoração. escarros sanguineos e suores profusos. No dia 11 de setembro foi-lhe feita a injecção da 2. dose. T. O. B2. A doente reagiu com u'ma pequena elevação de temperatura. cuja maxima attingiu, no dia 13 , a $38^{\circ} .7$; cs 
escarros sanguineos continuaram do mesmo modo que a tosse e os suores noturnos.

2. ${ }^{\mathrm{n}}$ quinzena de setembro: Applicação da 3.' dose de T. O. B2. Não houve reacção thermica. Os escarros sanguineos a tosse e os suores continuaram.

Dia 27 de setembro. Injeç̧ão da IV dose de T. O. B2. Siem reacção, o typo febril tende a normalizar-se. Maximas de $38^{\circ}$. Minimas de $35^{\circ}, 4$. Escarros sanguineos, tosse e suores.

1." quinzena de outubro: - Dia 4. Applicação da V dose de T. 0. B2. sem reacção thermica notavel. Tosse, escarros hemóptoicos e suores.

Dia 13. Injecção da VI dos€ de T. O. B2. Sem reacção. Os escarros teudem a diminuir.

2. quinzena de outubro: - Dia 21. Injeção da VII dose de T. O. B2. Obtem-se o primeiru periodo de apyrexia após 7 mezes de molestia. Poucos escarros. A tosse e os suores continuam.

Dia 30. Applicação da VIII dose de T. O. B2. Reacção thermica que attinge a $38^{\circ}, 2$ e que dura até ao dia 4 de novemibro. Escarros hemoptoicos abundantes. A tosse continua intensa; suores em declinio.

1. quinzena de novembro: - Dia 11. Repetição da VIII dose de 'T. O. B2. Diminue a tosse; poucos escarros, suores quasi desapparecidos. Sem reacção thermica.

2. quinzena de novembro: Dia 19. Applicição da IX dose de T. O. B2. Não houve reacção thermica. Estabelece-se a apyrexia. Maximas de $37^{\circ}$, minimas de $35^{\circ}, 8$. Tosse diminuida. Poucos escarros. Suores quasi desapparecidos.

Dia 27. Injecção da $X$ dose de T. O. B2. Sem reacção.

1." quinzena de dezembro: - Dia 5. Injecção da XI dose de T. O. F2. Reacção thermica de $0^{\circ}, 5$. Sem escarros. Sem suores e quasi sem tosse. Pequena reacção local.

2.a quinzena de dezembro.

Dia 17. Injecção de $2 \mid 3$ da XI dose de T. O. B2. ISem tosse, sem escarros e sem suores. A doente continúa apyretica.

Dia 25. Repetição de $2 \mid 3$ da XI, dose de T. O. B2. 'Sem febre, sem tosse. sem escarros e sem suores.

Do caso clinico em questão, pode-se ter noção exacta, pela seguinte carta, em que o DR. CARDOZO FONTE sobre elle se pronuncia:

"Rio de Janeiro, 6 de fevereiro de 1919.

Prezado collega Sr. Dr. ANTONIO CARDOZO FONTES.

Apresentando os mais respeitosos cumprimentos, envio-lhe uma rota succinta a respeito da doente de que ha poucos dias falamos. 
Pulmão direito: anteriormente $\mathrm{n}_{0}$ lobo superior e parte do medio, submacissez, exaggero das vibrações vocaes, sopro, estertores sibilantes e subcrepitantes medios e finos e, dahi para baixo, murmurio vesicular aspero; posteriormente, no lobo superior, estertores subicrepitantes medios e finos, submacissez e sopro.

Pulmão esquerdo, anteriormente no lobo superior, submacissez com estertores subcrepitantes finos; posteriormente respiração aspera no lobo superior.

Tosse constante, expectoração muco-purulenta \& muito frequente mente sanguinea. Temperatura elevada e pulso frequente, conforme as notas fornecidas. Suores nocturnos. Todos esses symptomas se mantiveram sem modificação sensivel durante os mezes de agosto a setembro, tendo eu deixado de prestar serviços a doente em principio de outubro, por motivo de molestia.

Pelo distincto collega, que me substituiu (1) fui informado de que em fins de outubro os sylmptomas referidos começaram a se modificar favoravelmente, dahi por diante essas melhoras se foram accentuando francamente, de modo que, quando, em 25 de dezembro, examinei a doente, verifiquei ausencia de estertores, da submacissez e do sopro, havendo apenas respiração aspera nos pontos mencionados; desapparecimento da tosse, dos escarros e dos suores nocturnos; temperatura e pulso normaes; bom apetite, augmento de peso; estado geral bastante satisfactorio.

São estas as informações que, em resumo, lhe posso fornecer, ficando ao dispor do distincto collega e subscrevendo-me com o mais elevado apreço.

Collega am.' cr.' e obr.' (Assignado) CARDOZO FONTE"

Pelo que se leu, eram em dezembro de 1919. magnificas as condições da doente, que desde maio do referido anno havia sido aconselhada pelo eminente clinico, PROF. ROCHA FARIA, a fazer uso do tratamento especifico, conforme a carta que se segue, e que só me foi entregue dois mezes depois:

"Prezado collega Sr. Dr. A. FONTES.

Saudações.

A doente, portadora desta, veiu ao meu consultorio ha poucos dias; padiece de phymatose de evolução sub-agudı e parece-me em condições ainda regulares para colher do tratamento especifico bom proveito.

Ha accessos febris diarios e o maximo thermico oscilla nelles entre $38^{\circ}, 5$ e $39^{\circ}$.

(1) Dr. Sebastião das Neves. (Nota do A. do artigo). 
Recommendo-a á sua habitual attenção e conto ve-la em accentua. das melhoras com o seu tratamento convenientemente applicado.

Do am." collega e admo. (Assignado) ROCHA FARIA".

Acha-se a doente hoje em dia curada, tendo se submettido a uma nova serie tuberculinica, no inverno passado sem apresentar nenhuma reacção.

Tive occasião de examina-la em fins de janeiro do corrente anno e constatar a consolidação da cura obtida.

Vereis por ella a possibilidade do tratamento pela tuberculina modificada de casos de tuberculose febril congestiva de evolucão sub-aguda. obtendo-se a immunização activa do paciente, mešmo na vigencia de constantes periodos congestivos que não só foram agravados, como corrigidos.

Na prophylaxia da tuberculose entra pois, meus senhores, a tuberculina como factor de duplo effeito: revelando o portador ou disseminador de virus e extinguindo o fóco de infecção.

Ainda ha pouco o eminente tisiologo patricio, o Dr. CLEMENTE FERREIRA, em excellente memoria, apresentada ao 1.' Congresso Brasileiro de Proteção á Infancia, em que trata da "Frequencir da Tuberculose Infantil e Assistencia da Criança tuberculosa", deixou patente, por detalhado estudo de estatisticas mundiaes, que a infecção tuberculosa é, em quasi totalidade dos casos, adquirida na primeira infancia, succumbindo o lactante na proporção de 70 a 80 olo. Infecção por contagio familiar que praticamente póde ser considerado exclusivo, deve sobre elle incidir todo o esforço do hygienista, preparando gerações novas, isentas da infecção bacillar, reconhecend: precocemente a infecção pela reacção diagnostica turberculina, dominando o afastamento das crianças indemnes predispostas que devem ser collocadas em condição de melhor elevação do coefficiente de sua resistencia, extinguindo o fóco da tuberculose latente ou aberta com a pratica tuberculinica alliada ás medidas adjuvantes de tão complexa prophylaxia. até que chegue o dia, que creio não estar inuito distante, em que a vaccina antituberculosa, de vez, afaste da humanidade o espectro da peste branca. Tendem para esse objectivo os esforços dos microbiologistas. Com as esperanças, lançadas por BEHRING pelos resultados, que obteve na imimunização antituberculosa com a bovo-vaccinação, que a pratica infelizmente não sanccionou tem a experimentação se succedido ininterruptamente, ora desilludida por desenganos ora recompensada em acquisição de factos promissores da solução do problema. A vaccinação antitubercular tem que visar, meus senhores, não só a immunização anti-tuberculinic: 
como a produção, de anticorpos especificos, como a immunisaçãs contra a cellula parasita. $E$, nesse objectivo experimentam os microbiologistas obtel-a ensaiando os virus mortos ou attenuados pelos differentes agentes physico-chimicos ou biologicos, utilizando nesse mister as varias raças do virus, humano, bovino, aviario, ou dos animaes de sangue frio, e variando as vias de introducção, assim como a dóse a experimentar. As escolas de BEHRING, MARAGLIANO, CALMETE e TERRAN de ha muito vem illustrando o assumpto. sem que os resultados dos seus estudos possam em tudo ser considerados como acquisições definitivas.

Enveredei, tambem por ahi a minha curiosidade scientifica, e, $\leqslant$ até agora os resultados obtidos não me autorizam a julgar proxim: a solução do problema, dão-me alento e fé para que não abandone essa via de experimentação, com a esperança rémota de concorrer com meu esforço na maior obra de benemerencia para a humanidade.

Emquanto, meus senhores, que na vaccinação anti-tuberculinica se consegue obter um estado de immunidade activa com os productos retirados chimica ou mechanicamente dos corpos bacillares, triturando-os ou dissolvendo-os pelos reagentes os mais diversos. na immunisação antitubercular nada se consegue de positivo com o emprego dos residuos bacillares, ou dos elementos infectuosos mortos palo calor, pela luz ou reagente chimico qualquer, inda que sua morpholojgia e estructura não sejam alteradas. Alguns resultados encoraja. dores teem sido, entretanto, obtidos quando se procede á inoculação de uma variedade de virus que, conservando a vida, apresenta suas propriedades alteradas no sentido da diminuição dos seus effeitos necrosantes e inflammatorios, de sorte a ser possivel a reabsorpção dos elementos figurados, que em dóses crescentes poderão conferir um augmento de resistencia notavel ao organismo sensivel, por sua vez capaz de assegurar-lhe um estado de immunidade praticamente utilisavel.

Tendem nesse sentido as ultimas experimentações registradas em sciencia e, se se confirmarem os resultados annunciados por FERRAN, em virtude da sua original concepção sobre o saprophytismo do bacillo da tuberculose. ou os de CALMETTE com a modificação e attenuação dos bacillos pelos meios biliares, em breve entrará o problema em via de franca resolução.

Penso, meus senhores, que aos lipoides. substancias estas tão mal conhecidas, ainda estará reservado preponderante papel nesse desideratum, e nesse caminho orientando minhas investigações, perseve. rarei até que novas desillusões me obriguem a delle afastar-me, sem que me falleça a fé nos destinos da sciencia. para maior beneficio da humanidade. 